\title{
Health Outcomes in Sub-Saharan Africa Countries: An Analysis of Key Determinants
}

\author{
Timothy Oladayo Popoola ${ }^{1}$ \\ ${ }^{1}$ Department of Economics, Ahmadu Bello University, Zaria, Nigeria \\ Correspondence: Timothy Oladayo Popoola, Department of Economics, Ahmadu Bello University, Zaria, Nigeria. \\ Tel: 234-(0)813-574-5100. Email: poladayo@ gmail.com
}

Received: March 17, 2018; Accepted: April 20, 2018; Published: May 21, 2018

\begin{abstract}
The poor health outcomes (low longevity and high mortalities) in developing countries has been great concern for citizens and policy makers alike. Although, numerous studies have focus on socio-economic drivers (like education, age of mothers, income levels, and poverty) of health outcomes in developing nations; however, the same is not true for important exogenous determinants. Therefore, this study investigated the effects of access to clean drinkable water, sanitation, fertility rate, prevalence of HIV/AIDS, health financing, and child immunization on health outcomes in sub-Sahara African (SSA) region. To achieve this, the study explored Pooled OLS, Fixed and Random Effects covering 46 countries in the region from 2000 to 2015. The findings reveal that population health outcomes - as measured by infant and under-five mortalities rates are related negatively with increase public health financing, timely children immunization, quality drinkable water supply, but directly associated with higher fertility rate, and HIV prevalence. For life expectancy at birth, increase government health spending, timely children immunization, and quality drinkable water supply are positively predicted, while relate inversely with higher fertility rate, and HIV prevalence. The findings therefore suggest that for SSA countries to achieve the United Nations' Sustainable Development Goal three of ensuring healthy lives before 2030; emphasis should on increasing public health financing, and provision of infrastructural facilities like clean water supply and sanitation. Again, greater attention should be on enhancing child immunization, reducing fertility rates and HIV prevalence in the region.
\end{abstract}

Keywords: Health, Human Capita, SSA, Panel Data Estimation

\section{Introduction}

The need for healthy population in fostering economic growth is well recognized in literature ${ }^{1}$. As World Bank (2017) and World Health Organization (2016) emphasized, healthy citizens are one of the critical ingredient of economic growth that developing countries should pursue. This implies that health is a capital good and its enhancement is an important driver of efficient human capital and economic growth. Again, healthy outcomes have far-reaching implications for change, quality of life and development (Linden and Ray, 2017). This further suggest that healthy outcomes (in addition to education) are the prime beneficiary of welfare development of citizens, as it affects not only the number of days that citizens would dedicate to their economic activities, but also the very decision of participating in economic productivities. In recent three decades however, Sub-Saharan African (SSA) nations experiences lowest average life expectancy at birth, highest infant and maternal mortalities rates comparatively to other regions. Malaria, tuberculosis, stroke, HIV/AIDS and all forms of cancer are also major characteristic of her countries with untold negative effect on her citizens' health. In specific terms, the life expectancy (on average) for the SSA region was as low as 58-year-old. For Middle East and North Africa (MENA) and East Asia and the Pacific (EAP), the longevity as higher at 73 and 75 respectively in year 2015 (Novignon et al. 2015; World Bank, 2017). The region also experienced the highest under-five mortality (U5M) and infant mortality rate (IMR) of 83.1 and 56.3 (per 1,000) respectively; while MENA and EAP has far low statistics of 23.3 and 19.6 (per 1,000) for U5M and 17.1 and 14 (per 1,000) for IMR respectively in the same year (World Bank, 2017).

As WHO (2016) and Novignon et al. (2015) observed, several countries in SSA region (including Nigeria) lagged behind in meeting the recent past Millennium Development Goals (MDGs). For example, Nigeria (the largest and one of the oil exporter in the region) loses on average 2,300 under-five year olds children daily which makes the country the second largest contributor to maternal and under-five mortalities worldwide after Republic of Chad 
(UNICEF, 2015; WHO, 2016). Numerous evidence from literature also established that health outcomes are generally poor in the region (UNICEF, 2015; World Bank, 2015; and WHO, 2016).

Although, there is extensive literature ${ }^{2}$ on major drivers of health outcomes in developed nations. However, evidence from developing countries largely focus on socio-economic drivers like age of mothers, education, income level, and poverty (Fayissa and Gutema, 2005; Grepin and Bharadwaj, 2015; and Demonbynes and Trommlevova, 2016). However, important exogenous factors that are largely beyond the citizens' ability (such as, clean drinkable water supply, sanitation, public health spending, child immunization, and fertility rate) were lacking from these studies. Thus this study added to existing literature by exploring data from 46 SSA countries for the period of 2000 to 2015. The study employed Panel regression technique to answer its research question of: what major factors associated with the poor health outcomes of citizens in SSA region?

Essentially, the study would serve as guide to policy makers to facilitates the achievement of health-related targets of Sustainable Development Goal three (SDG 3), with the ultimate aim of enhancing healthier labour force and increase economic productivity in the region. To achieve these, the study is structured as follows: section two contained previous studies; section three presents the methods - analytical framework, model specification, and econometrics methods; while panel regression findings, and its interpretations are presented in section four. Lastly, section five concludes and suggests some health-policy recommendations.

\section{Literature Review}

Conceptually, health outcomes are changes in the health status of an individual, household or population. It is also the results of health conditions that directly affects the length or quality of people's life (Modern Medicine Dictionary, 2002). Health outcomes is also seen as the quality of life especially at the macro-level and on a comparable basis across nations (Or, 2000). Therefore, citizens' health outcomes could either be negative or positive. The former concerns illnesses, lack of well-being, disability, and mortalities. While the latter relate to being alive and healthy, functioning well mentally, physically, socially, and having a sense of well-being. Again, the positive population health outcomes imply an improvement in nutrition or healthy society (Oxford Health Alliance, 2006). This is because enhanced population health relates to an improvement in cognitive development, particularly in early childhood (which leads to their ability to learn), and an improvement in the human capital development.

Most often, healthy children learn fast and gain more from school, because of the tendency of having fewer days absent from school due to ill health. Similarly, enhanced population health of adults will add to labour force participation and human capital - a key driver of economic growth and development (Grossman 1972); but negative population health outcomes reduces economic activities. This further suggest that healthy outcomes play a crucial role in economic development as it constitutes a key component of human capital and labour force participation.

There are various indicators of health outcomes like mortalities, morbidity, diseases burden statistics, and life expectancy. The mortality rate is the number of deaths that occur at a specific time, in a specific population, or from a specific cause. There are also various types of mortalities. This includes infant, under-five and adult mortalities. Infant mortality refers to death before the first year of life - death during age of zero to 365 days (12 months). Under-five mortality relates to death between the first and the fifth birthday - death during age 12 to 59 months. These can be measured using information from birth histories of women of age 15-49 years (World Bank, 2017). In SSA region, studies consistently established that infant health outcomes are generally poor (Novignon et al. 2015, and Adedini, 2013). For instance, Rutherford et al. (2010) reported that in a global estimate of 9.7 million under-five deaths each year, $41 \%$ of these deaths occur in SSA nations. Similarly, UNICEF (2012) put the 2011 global under-five deaths at over 7 million, though childhood mortality seems to be declining in other regions of the world, the statistics still remains unacceptably high in SSA region as table 1 indicated.

Table 1. World Regional Under-five Mortality Rate (per 1,000)

\begin{tabular}{lllllll}
\hline & Global Average & SSA & Middle East \& North Africa & OECD members & East Asia \& Pacific & North America \\
\hline $\mathbf{2 0 0 0}$ & 75.9 & 154.83 & 42.70 & 12.89 & 39.97 & 8.23 \\
$\mathbf{2 0 0 5}$ & 62.6 & 127.23 & 34.19 & 10.16 & 29.47 & 7.85 \\
$\mathbf{2 0 1 0}$ & 51.7 & 101.40 & 27.65 & 8.42 & 22.06 & 7.25 \\
$\mathbf{2 0 1 5}$ & 42.5 & 83.18 & 23.34 & 6.89 & 17.11 & 6.36 \\
\hline
\end{tabular}

Source: Compiled from World Bank dataset (2017) 
From table 1, under-five mortality rate in SSA region is the highest in the world with an estimate of 83 under-five deaths in every 1,000 live births for 2015. Comparatively, the global average is 42 out of 1,000 live births in the same period. Another key health indicator is life expectancy (LEB). The LEB refers to the number of years (on average) an individual is expected to live (World Bank, 2016). This reflects the overall mortality level of citizens. Therefore, it concerns the mortality patterns that prevails in children, adults, and across all other age groups (WHO, 2016). For example, the average life expectancy at birth of Nigerian is a mere 53 years in 2015; while countries like Sierra Leone and Zimbabwe has lower life expectancy of 39 and 40 respectively (World Bank, 2017).

Table 2. World Regional Average Life Expectancy at birth (total)

\begin{tabular}{lllllll}
\hline & Global Average & SSA & Middle East \& North Africa & OECD members & East Asia \& Pacific & North America \\
\hline $\mathbf{2 0 0 0}$ & 67.6 & 50.3 & 69.8 & 77.1 & 71.4 & 76.9 \\
$\mathbf{2 0 0 5}$ & 69.0 & 52.7 & 71.0 & 78.2 & 73.1 & 77.8 \\
$\mathbf{2 0 1 0}$ & 70.5 & 56.3 & 72.1 & 79.5 & 74.2 & 78.8 \\
$\mathbf{2 0 1 5}$ & 71.7 & 58.9 & 73.1 & 80.3 & 75.1 & 79.1 \\
\hline
\end{tabular}

Source: Compiled from World Bank dataset (2017)

Table 2 depicts the average LEB across world's various regions. The statistics indicates that SSA regions performs relatively poorly relatively to MENA and EAP. Although the life expectancy (at average) for SSA region slightly improved between 2000 and 2015 from 50 to 58 years respectively. Often, the LEB is one of the key indicator of health status of nations with advantages; because it depends on infant, under-five, maternal, and other mortality rates (Linden and Ray, 2017). As Herzer and Nunnenkamp (2015) observed, LEB as key indicator of population health outcomes might not be the best indicator because there seem to be differences between longevity and health life expectancy. In spite of this insight, life expectancy can still be regarded as important aggregated health status of any nations (see Herzer and Nunnenkamp, 2015; and Bakkeli, 2016).

Theoretically, health outcomes of citizens are often influenced by various factors. Some of these factors are; employment status, income level, housing conditions, heating, education, diet, health financing, pollution and health lifestyle of citizens (Grossman, 1972). As Berkman, et al, (2000) and Grossman (1972) emphasizes, health outcomes of citizens in any economy could serve as fundamental commodity for every individual to function effectively in the economic outputs. The population allocates their resources to produce healthy living, which implies that the demand for health is a derived demand. The theory consisted of two elements - consumption and investment effects. The consumption effects assumed that health yields direct utility to individual, for instance, one will feel better when one is healthier; however, investment effects emphasis that healthy status could enhance labour force supply and human capital.

The model also emphasizes that positive healthy outcomes serves as fundamental factor that enhances human capital and economic growth. This is because individuals demand good health for two purposes: first, to take part in economic productivity; and second, for non-economic activities such as leisure. The first implies that health outcomes may influence the amount of economic output and numbers of labour supplied in an economy by shifting their preferences between leisure and productivity (Novignon et al. 2015). But the second suggests in the case where citizen have poor health status, they tend to value leisure time more or are probably forced to choose more leisure time over work time; this constrain economic output. In addition, one can attribute this to the fact that less healthy population are more likely to be stressed from work pressure; and less healthy individuals may also prefer to shift their preferences from productivity because of the financial burden that accompanies poor health (Cai and Kalb, 2005). Meanwhile, such health-improving activities require resources, including income to pay for healthcare costs. This suggests that health status of individuals could be considered as endogenous as people have to make choices in its production and their income level could also predict their health outcomes.

In terms of empirical evidence, numerous approaches were employed in literature. The first distinction in these approaches concerns the type of data used, where some studies employed aggregated macroeconomic data (see Ou et al. 2016; Lawson and Spear, 2016; Brock, Yinghua, and Zeng, 2015; Handa, 2000; Bhargava, Chowdhury, and Singh, 2005). Several others employed household data (Elder, Godderis, and Haider, 2016; Demonbynes and Trommlerova, 2016; Grepin and Bharadwaj, 2015; Pfutze, 2014; Estevan and Baland, 2007). Furthermore, some previous studies also relied on cross-sectional techniques (Liu and Mora, 2016; Buckler, Hagemann, Malamud, Morrill, and Wozaniak, 2016; Tanaka, 2015; Maiti and Petrie, 2014; Cruces, Gluzmann, and Calva, 2012; and 
Barham, 2011); others used panel techniques (Linden and Ray, 2017; Gamper-Rabindran, Khan, and Timmins, 2010; Eliot, Dean, and Hanushek, 2007).

From these studies, education was identified as critical factor explaining differences across countries in the numbers of mortalities and averages of life expectancy. In studies from developed nations, cross-sectional regressions on inefficient health outcomes (high IMR and U5R, and low average LEB) and education quality consistently showed negative results with large magnitudes (Buckler et al. 2016; Grepin and Bharadwaj, 2015; Esteran and Baland, 2007). Another study by Eliot et al. (2007) using panel techniques indicated similar findings in United States. Similarly, Leuven et al. (2013) used cross-sectional data in Netherlands and found that quality of medical schools was directly related to efficient health outcomes. But, in Zimbabwe, Grepin and Bharadwaj (2015) identified low maternal education as positively significant to high IMR and U5R.

Another is socio-economic status, and commonly used indicators are the age of mothers, education, and income levels of parents. These variables were also very significant in explaining health outcomes (Elder et al. 2016; and Maiti et al. 2014). Specifically, in using micro-level statistics data from 2000 to 2004, Elder et al. (2016) estimated the role of socio-economic status of health outcomes on United States citizens and found that maternal marital status, education levels, age, income levels, and poverty are major drivers of infant mortality gaps in United States. Maiti et al. (2014) used general equilibrium spatial structure and found that socio-economic characteristics, cultural and demographic phenomena determine health outcomes and health behavior in Scotland. In Africa, large-scale campaign and distribution of insecticide-treated bed-nets was found to significantly decline infant mortality in Kenya in 2000s (Demombynes and Trommlerova, 2016).

In a related study, Fayissa and Gutema (2005) used one- and two-way panel techniques to examined socioeconomic and environmental drivers of LE in 33 SSA nations from 1990 to 2000. They found that increase in food availability and fall in illiteracy increases LE in SSA nations. Furthermore, health expenditure was also seen as important driver of healthcare provision. For example, in a cross-sectional study in Argentina, Cruces, et al, 2012 indicates that low public expenditure accounts for high mortalities. Bhargava, Chowdhurry, and Singh (2005) also found the same results in India. In using stochastic frontier method, Brock, Yinghua and Zeng (2015) found that fiscal decentralization does not alleviates the problems of high IMR in China. However, in a more recent study, Ou et al. (2016) findings reveal positive nexus between increase in health expenditures and low life expectancy in Taiwan. In general, these studies explained the important of health technology in improving health status.

Recently, there has been much interest on the impact of per capita (income level and living standard of citizens) on health outcomes. Linden and Ray, (2017) used quantile regression approach on 148 nations for the years 1970 to 2010and found positive nexus between per capita income and high life expectancy. But, Lawson and Spear (2016) observes that adult wages of parents and early-life mortality of children are positively related in India. In addition, Barham (2011) in a study on rural Mexico obtained positive nexus between conditional cash transfers (CCT) and low neo-natal and infant mortality rates. Esteran and Beland (2007) found similar findings in Namur. However, Li and Mora (2016) found that grand-parents' income and old age allowances program reduces IMR in Nepal. Other major determinants include pollution and infrastructures. In a recent study, McCord et al. (2017) found direct nexus between temporal variation in ecology of the diseases and mortality of child. In another similar study, Tanaka (2015) observes that environmental regulations reduce the cost of air pollution which is positively related with high infant mortality in China. Another major factor paramount to health outcomes is drinkable water; because at worst some litres of safe water is important to health. Thus, evidence with the aid of quantile panel data techniques, Gramper-Rabindran, et al, (2010) found positive relationship between piped-water provision and low IMR in Brazil.

From the foregoing, recent empirical literature identified major determinants of population health outcomes; however, there might be problematic in attempting to adopt these findings wholesale in SSA countries; because majority of these empirics are based on data from either only developed economies (such studies includes, Ou et al. 2016; Liu and Mora, 2016; Buckler et al. 2016; Elder et al. 2016; Lawson and Spear, 2016; Brock et al. 2015; Tanaka, 2015; Maiti and Petrie, 2014; Cruces et al. 2012) or pooled data from both emerging and developed nations (Linden et al. 2017). Meanwhile, studies on developing countries were very scanty (these few studies includes, Demonbynes and Trommlerova, 2016; Grepin and Bharadwaj, 2015; and Fayissa and Gutema, 2005). One, water is often collected from communal unsafe sources (WHO/UNICEF, 2010); however, safe water is key to health which are lacking from these studies. Two, these studies did not consider sanitation and toilet facilities in improving health outcome; however clean and improved water supply is expected to improve healthy living of individual, households and health outcomes in emerging nations. 
Furthermore, of all these limited studies on developing countries, only the study of Fayissa and Gutema (2005) is devoted specifically to SSA region. One, the time period covered by this study is not very recent. Two, the study only used life expectancy (as indicator of health outcomes); however, very recent studies emphasized that infant and under-five mortalities could be very close to aggregate indicators of health outcomes (see the studies of McCord et al. 2017; Elder et al. 2016; Li and Mora, 2016; Lawson and Spear, 2016; and Buckler et al. 2016). Three, important variable that is beyond citizens' ability - improved sanitation facilities, clean drinking water availability, fertility policy to reduce the number of children per women, control of HIV prevalence, provision of children immunization, and increased health expenditure from both private organizations and governments are lacking from the previous studies. Four, the study also differs from existing literature in that the study will focus on the 46 countries in SSA region.

\section{Methods}

\subsection{Analytical Framework}

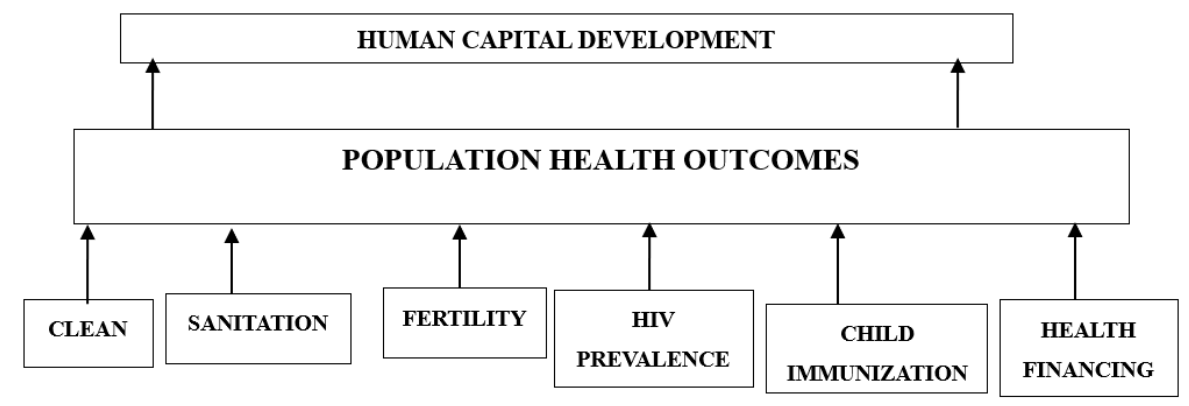

Figure 1. Framework for Health Outcomes in SSA Region

Source: Author's Initiative, 2017

Exposition from figure 1 above reveal critical drivers of health outcomes that include; clean drinking water, sanitation, health financing, literacy level of female, and child immunization. For example, quality of water supply is paramount to health, but safe water sources are with substantial distances from dwelling of households in SSA nations (WHO/UNICEF, 2010). Hence, clean drinking water is expected to lead to positive health outcomes of citizens' in SSA nations.

In addition, improving sanitation facilities (ISF) relates to preventing illness via managing the environment or reducing exposure to agents of diseases. However, majority of citizens in SSA countries lack quality sanitation (WHO/UNICEF, 2010). Furthermore, deadly diseases are attributed to poor sanitation (Black, 2010). Another factor paramount to citizens' health outcomes is amount of public and private health financing to provide health facilities in these countries. Quality health infrastructure through health spending are expected to provide ample facilities to citizens. Therefore, increased health expenditures are expected to exert a positive influence on population health outcomes $(\mathrm{H})$ of citizen. Others important factors is high fertility rate of 15-49 years of females, HIV/AIDS prevalence, and insufficiency child immunization are also expected to leads to poor health outcomes of citizens most especially infants and young mothers.

\subsection{Model Specification}

The analytical structure (see figure 1) is in the spirit of seminal contribution by Grossman (1972), where citizens' health outcomes are attributed to various drivers. Again, healthy outcomes drive human capital to achieve more economic growth (Romer, 1986). Thus,

$$
H_{i t}=f\left(X_{i t}\right)
$$

where $H$ represents health outcomes of citizens; $\mathrm{X}$ denotes vectors of determinants of health outcomes such as; clean drinking water supply (IWS), sanitation (ISF), fertility rate among mothers (FLR), prevalence of HIV/AIDS (HIV), child immunization (CIM), and health financing (PHE). Functionally,

$$
H_{i t}=f\left(I W S_{i t}, P H E_{i t}, F L R_{i t}, C I M_{i t}, H I V_{i t}, I S F_{i t}\right)
$$

where the subscript $i$ denotes sample nations in SSA region, and $t$ the time periods the study covered (2000-2015). The model is also consistent with the exposition from precious studies like Linden and Ray (2017). However, this model differs in that this study included the other variables like IWS, PHE, FLR, CIM, HIV, and ISF. In contrast, Linden and Ray (2017) employed quartile regression and consider pollution as driver of health outcomes, and life 
expectancy at birth (LET) as dependent variable. For the purpose of estimation, this study employed panel estimation techniques. As Baltagi (2008) noted panel technique often provides better understanding in this case. Thus, this study estimated a more restrictive pooled panel that assumes parameter homogeneity, and cross-section independence. However, severe biases can arise if observations are pooled because SSA nations are hetergeneous. Hence, as a standard approach in econometrics literature in estimating panel data model of various effects (fixed and random). This study expressed equation 3 as:

$$
H_{i t}=\alpha_{o}+\beta_{1} I W S_{i t}+\beta_{2} P H E_{i t}+\beta_{3} F L R_{i t}+\beta_{4} C I M_{i t}+\beta_{5} H I V_{i t}+\beta_{6} I S F_{i t}+\mu_{i}+v_{i t}
$$

where $H_{i t}$ is vector of population health outcomes. For $H_{i t}$, the study relies on life expectancy total (LET), infant mortality rate (IMR), and under-five mortality rate (U5M). From the model, $\mu$ denotes the regional/countryspecific unobserved effects, while $\beta_{1}, \ldots, \beta_{6}$ are coefficients of independent variables, and $\mathrm{v}$ the disturbance terms. The study also performed robustness checks using the Hausman's test to determine the best efficient estimator between FE and RE.

\subsection{Data}

The annual data sourced for the study are from World Bank Indicators (WDI, 2017) covering 2000 to 2015. The period corresponds with United Nations' Millemium Development Goals on enhancing health status of all citizens in the world. The study considered 46 nations in SSA region ${ }^{3}$.

\section{Empirical Findings}

\subsection{General Descriptive Results}

Table 3. Descriptive Statistics Table

\begin{tabular}{lccccc}
\hline Variables & Observation & Mean & S.D & Minimum & Maximum \\
\hline Life Expectancy at birth (total) & 736 & 55.9 & 7.23 & 38.7 & 74.4 \\
Infant Mortality Rate & 736 & 66.8 & 26.0 & 11.7 & 143.3 \\
Under-five Mortality & 736 & 103.8 & 45.6 & 13.5 & 235.8 \\
Fertility Rate of 15-49 years old women & 736 & 5.1 & 1.3 & 1.4 & 7.7 \\
Health Expenditure (total) & 736 & $5,592.2$ & $2,206.4$ & $1,412.9$ & $14,465.5$ \\
Children Immunization & 736 & 72.1 & 18.5 & 16 & 99 \\
Improved Water Supply & 736 & 32.7 & 21.8 & 6 & 98.4 \\
Improved Sanitation Facility & 736 & 67.6 & 16.9 & 23.5 & 99.9 \\
HIV prevalence & 736 & 5.8 & 6.8 & 0.3 & 28.8 \\
\hline
\end{tabular}

Source: Author's compilation using Stata 13

The descriptive statistics as presented in table 3 reveals that the average value of LET was as low as 38.7 years old. For instance, the LET in Sierra Leone, Zimbabwe and Swaziland are merely 39, 40, and 43 years old in 2000, 2003 and 2005 respectively. In addition, the average value of U5M in SSA nations is as high as 236 deaths in every 1,000 before their fifth year of births. While table 4 show the correlation matrix for the variables; where there is direct correlation between independent variables (CIM, ISF, and IWS) and LE, while (FLR, PHE, and HIV prevalence) are negatively related with LE as apriorily expected.

Table 4. Correlation Matrix Table

\begin{tabular}{lllllllll}
\hline & LE & IMR & U5M & FR & CI & ISF & IWS & HIV \\
\hline LE & 1.00 & -0.37 & -0.40 & -0.15 & 0.25 & 0.06 & 0.01 & -0.25 \\
IMR & -0.37 & 1.00 & 0.97 & 0.71 & -0.61 & -0.46 & -0.63 & -0.08 \\
U5M & -0.40 & 0.97 & 1.00 & 0.76 & -0.63 & -0.47 & -0.64 & -0.11 \\
FLR & -0.15 & 0.71 & 0.76 & 1.00 & -0.50 & -0.59 & -0.68 & -0.28 \\
CIM & 0.25 & -0.61 & -0.63 & -0.50 & 1.00 & 0.39 & 0.54 & 0.22 \\
ISF & 0.06 & -0.46 & -0.47 & -0.59 & 0.39 & 1.00 & 0.51 & 0.20 \\
IWS & 0.01 & -0.63 & -0.64 & -0.68 & 0.54 & 0.51 & 1.00 & 0.23 \\
HIV & -0.25 & -0.08 & -0.11 & -0.28 & 0.22 & 0.20 & 0.23 & 1.00 \\
\hline
\end{tabular}

Source: Author's computation using Stata 13 


\subsection{Panel Unit Root Test}

Another empirical contribution of this paper is the tests of whether LE, IMR, U5M, FR, HE, CI, ISF, IWS, and HIV are time-stationary or not. Fisher-type (Choi, 2001), Levin-Lin-Chu (1992, 2002), and Im-Pesaran-Shin (1997, 2003) tests have as the null hypothesis that all the panels contain a unit root. While LLC assumes a common autoregressive parameter and involves fitting an Augmented Dickey-Fuller regression (where the number of lags to include could be selected based on information criterion); IPS allows for heterogeneity on the lagged level term. However, Maddala and Wu (1999) and Choi (2001) consider the weaknesses of both LLC and IPS tests by suggesting the use of non-parametric Fisher-type tests, that often conduct unit-root tests for each time series individually and combines the p-values from these tests to produce an overall test.

Table 5. Panel Unit Root Test Results

\begin{tabular}{|c|c|c|c|c|c|c|}
\hline \multirow[b]{2}{*}{ Variables } & \multirow{2}{*}{$\begin{array}{l}\text { Level } \\
\text { LLC }\end{array}$} & \multirow[b]{2}{*}{ IPS } & \multirow[b]{2}{*}{ FISHER } & \multicolumn{2}{|c|}{ First different } & \multirow[b]{2}{*}{ FISHER } \\
\hline & & & & LLC & IPS & \\
\hline$L E$ & $-6.09 * * *$ & -7.85 & $19.12 * * *$ & $-40.29 * * *$ & $-46.99 * * *$ & $123.10 * * *$ \\
\hline$I M R$ & $-36.25 * * *$ & $-25.18 * * *$ & $77.42 * * *$ & $-17.89 * * *$ & $-7.43 * * *$ & $31.51 * * *$ \\
\hline$U 5 M$ & $-36.68 * * *$ & $-32.79 * * *$ & $84.31 * * *$ & $-26.97 * * *$ & $-13.83 * * *$ & $45.46 * * *$ \\
\hline$F R$ & 6.73 & 30.26 & $20.70^{*}$ & $-6.37 * * *$ & $2.64 *$ & $25.53 * * *$ \\
\hline$H E$ & $-5.49 * * *$ & -2.91 & $5.26 * * *$ & $-4.22 * * *$ & $-0.77 *$ & $5.12 * * *$ \\
\hline$C I$ & $-6.63 * * *$ & $-2.30^{* *}$ & $3.47 * * *$ & $-7.58 * * *$ & $-2.76 * * *$ & $3.87^{* * *}$ \\
\hline$I S F$ & $-8.23 *$ & -4.12 & $5.29 * *$ & $-0.23^{*}$ & $-2.09 *$ & $5.24 * * *$ \\
\hline$I W S$ & $0.37 *$ & 0.05 & $10.48^{* * *}$ & $0.42^{*}$ & $0.02 *$ & $11.02 * * *$ \\
\hline$H I V$ & $-11.11 * * *$ & $-2.82 *$ & $25.09 * * *$ & $-10.01 * * *$ & $-2.06^{* *}$ & $25.90 * * *$ \\
\hline
\end{tabular}

Note: $*, * *$, and $* * *$ denotes $10 \%, 5 \%$, and $1 \%$ respectively.

Time trends was considered because all has trends from graphing.

Source: Compiled by the Author using Stata 13

As table 5 revealed, the results show that except fertility rate, improved sanitation facility, and improved water supply, at least either the LLC or IPS statistics indicates that the variables are stationary at level. In contrarily, Fisher test (as proposed by Maddala and Wu, 1999; and Choi, 2001) show that all the variables do not contain unit root at level. Thus, considering the Fisher's tests, this study concludes that they all follow stationary process and reject the null hypotheses of presence of unit roots. Hence, the study employed the pooled OLS, Fixed Effects, and Random Effects.

\subsection{Panel Regression Results}

Table 6. Pooled OLS, Fixed and Random Effects Regressions

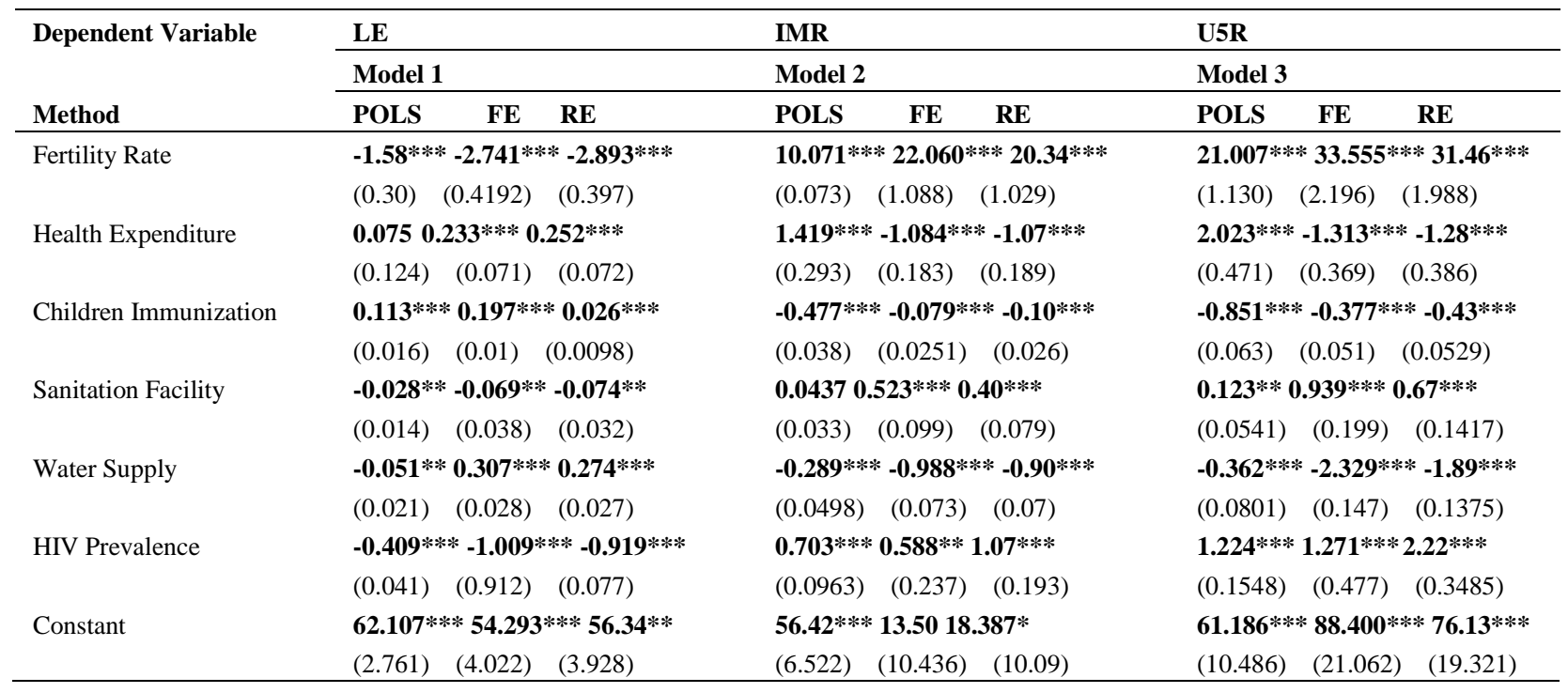




\begin{tabular}{llllllllll}
\hline R-squared & 0.194 & 0.6533 & 0.6524 & 0.652 & 0.8249 & 0.8229 & 0.705 & 0.8133 & 0.8098 \\
Prob. & 0.0000 & 0.0000 & 0.000 & 0.0000 & 0.0000 & 0.0000 & 0.0000 & 0.0000 & 0.0000 \\
Obs. & 736 & 736 & 736 & 736 & 736 & 736 & 736 & 736 & 736 \\
\hline
\end{tabular}

Notes: $\quad 1 . * * *$ significance at $1 \%$; **significance at $5 \%$; *significance at $10 \%$

2. Robust standard errors are reported in parentheses

Source: Author's computation using Stata 13

From table 6 above, all variables appear to have the correct a-priori signs except IWS, and HE in pooled OLS which contradict Grossman (1972) theoretical explanations of the effect of IWS and HE on LE, IMR, and U5R. In particular, the intercept $\boldsymbol{\alpha}_{i}$ of FE are largely significant at least at $1 \%$. Hence, this study can conclude that pooled OLS is insignificant as it assumes that all the countries are homogenous. However, the finding indicated that SSA countries are heterogenous ${ }^{4}$.

For FE (see model 1,2, and 3), the signs of all the coefficients except ISF confirm with the study a-priori expectation. For example, in model 1, the coefficients of FR, HE, CI, IWS, HIV, and ISF (-2.74, 0.23, 0.19, 0.31, -1.01 , and -0.07) were all statistically significant. Again, all the coefficients of FR, HE, CI, IWS, HIV, and ISF (22.06, -1.08, -0.08, -0.99, 0.59, and 0.52) and (33.56, -1.31, -0.38, -2.33, 1.27, 88.40, and 0.94) in model 2 and 3 were also significant respectively. The probability values for the three models was very low $(0.0000)$ which show that the models are highly significant. Furthermore, the RE finding supported FE but with slight difference in magnitude. The coefficients sign of fertility rate, total health expenditure, children immunization, quality drinking water, and HIV prevalence except improved sanitation facility also confirm the study a-priori expectation. The coefficients of FR, HE, CI, IWS, HIV, and ISF in models 1, 2, and 3 respectively were all also statistically significant at 1 per cent level, where the probability is 0.000 .

The major difference between FE and RE depend on the assumption on intercept $(\alpha)$ and the explanatory variables (X) correlation. Specifically, if they are uncorrected, the RE estimator is consistent and efficient. The FE estimator is consistent but not efficient, but the RE estimator is now inconsistent. It is therefore natural to proceed by computing the $\mathrm{Wu}$-Hausman specification test to identify which estimator is the best. For model 1, the calculated Hausman statistic (see appendix A2) and distributed chi-square are 36.63 and 0.0000 respectively; for model 2, 36.30 and 0.0000; and for model 3 the values are 66.66 and 0.0000 . These reveals that for all the models the $\mathrm{p}$ values $<0.05$ ( $5 \%$ level), therefore it is appropriate to interprets the fixed effect models. From FE results, model 1 suggest that policy efforts that emphasizes on quality drinking water, low fertility rate, health spending, sanitation, children immunization, and low HIV prevalence are key to higher life expectancy in all SSA countries. In addition, both model 2 and 3 similarly suggest that to reduce under-five, and infant mortality rates in SSA nations, quality water supply, and sanitation are paramount (this is because IWS and ISF are negatively related and highly significant). The results were consistent with the results obtained by McCord et al. (2017) that temporal variation in children diseases rises as pollution rises which resulted to high infant mortality rate (IMR).

\section{Conclusion and Policy Recommendations}

\subsection{Summary and Policy Implications}

The study set out to investigate major determinants of population health outcomes from recent 2000 to 2016 across 46 SSA countries using panel model analysis. The findings suggest that safe water supply, low fertility rate, higher health expenditure, timely children immunization, low HIV prevalence, and sanitation are paramount to improved life expectancy in these nations. Furthermore, to reduce under-five mortality and infant mortality rates in these nations, water supply and its quality; sanitation, access to toilet facilities and clean environment, low fertility rate, higher health expenditure, timely children immunization, and low HIV prevalence are paramount.

The findings therefore call for effective policy at providing water and sanitation facilities, and reducing fertility rate, increase health expenditure, enhance the provision of children immunization, and lower HIV prevalence to improve population health outcomes. Emphasis should also be on enhancing standard of living. In addition, efforts should be directed towards increasing health expenditure, provision of infrastructural facilities such as, water supply, and sanitation. And greater attention should draw to reducing fertility rate of women between the ages 1549 years old. In addition, focus should be on enhancing child immunization and control of HIV prevalence in the region.

\section{Reference}

Barham, T. (2011). A healthier start: The Effect of Conditional Cash transfers on Neonatal and Infant 
Mortality in rural Mexico. Journal of Development Economics, 94(1), 74-85. https://doi.org/10.1016/j.jdeveco.2010.01.003

Bhargava, A., Chowdhury, S., \& Singh, K. K. (2005). Healthcare Infrastructure, Contraceptive use and Infant Mortality in Uttar Pradesh India. Economic and Human Biology, 3, 388-404. https://doi.org/10.1016/j.ehb.2005.09.001

Bhattacharjee, A., Maiti, T., \& Petrie, D. (2014). General Equilibrium Effects of Spatial Structure: Health Outcomes and Health Economics in Scotland. Regional and Urban Economics, 49, 286-297. https://doi.org/10.1016/j.regsciurbeco.2014.10.003

Brock, G., Yinghua, J., \& Zeng, T. (2015). Fiscal Decentralization and China's Regional Infant Mortality. Journal of Policy Modeling, 37(2), 175-188. https://doi.org/10.1016/j.jpolmod.2015.03.001

Buckler, K., Hagemann, A., Malamud, O., Morill, M., \& Woznick, A. (2016). Effect of College Education on Mortality. Journal of Health Economics, 50, 99-114. https://doi.org/10.1016/j.jhealeco.2016.08.002

Cho, I. (2001). Unit Root Tests for Panel data. Journal of International Money and Finance, 20, 240-272. https://doi.org/10.1016/S0261-5606(00)00048-6

Cruces, G. G., \& Calva, L. P. (2012). Economic Crises, Maternal and Infant Mortality, Low Birth Weight and Enrolment rates: Evidence from Argetina's Down turns. World Development, 40(2), 303-314. https://doi.org/10.1016/j.worlddev.2011.07.014

Demombynes, G., \& Trommlevova, S. K. (2016). What has driven the decline of Infant Mortality in Kenya in the 2000s. Economics and Human Biology, 21, 17-32. https://doi.org/10.1016/j.ehb.2015.11.004

Elder, T. E., Goddeeris, T. H., \& Haider, S. J. (2016). Racial and Ethnic Infant Mortality Gaps and the Role of Socio-economic status. Labour Economics, 43, 42-54. https://doi.org/10.1016/j.labeco.2016.04.001

Eliot, A. J., Dean, T. J., \& Hanushek, E. A. (2007). The Effects of Education Quality on Income Growth and Mortality decline. Economics of Education Review, 26(6), 771-788. https://doi.org/10.1016/j.econedurev.2007.07.001

Estevan, F., \& Baland, J. (2007). Mortality Risks, Education and Child Labour. Journal of Development Economics, 84(1), 118-137. https://doi.org/10.1016/j.jdeveco.2006.10.003

Fayissa, B., \& Gutema, P. (2005). The Determinants of Health status in SSA. American Economist, 49(2), 60-66. https://doi.org/10.1177/056943450504900207

Gamper-Rabindran, S., Khan, S., \& Timmins, C. (2010). The Impact of Piped Water Provision on Infant Mortality in Brazil: A Quantile Panel Data Approach. Journal of Development Economics, 92(2), 188-200. https://doi.org/10.1016/j.jdeveco.2009.02.006

Grepin, K. A., \& Bharadwaj, P. (2015). Maternal Education and Child Mortality in Zimbabwe. Journal of Health Economics, 44, 97-117. https://doi.org/10.1016/j.jhealeco.2015.08.003

Handa, S. (2000). The Impact of Education, Income and Mortality on Fertility in Jamaica. World Development, 28(1), 173-186. https://doi.org/10.1016/S0305-750X(99)00114-X

Im, K. S., Pesaran, M. H., \& Shin, Y. (2003). Testing for Unit Root in Heterogeneous Panels. Journal of Econometrics, 115, 53-74. https://doi.org/10.1016/S0304-4076(03)00092-7

Lawson N. and D. Spear (2016). What doesn't kill you makes you poorer: Adult wages and Early- life Mortality in India. Economics and Human Biology, 21, 1-16. https://doi.org/10.1016/j.ehb.2015.11.006

Leven, E., Oosterbeck, H., \& Wolf, I. (2003). The Effects of Medical School on Health Outcomes: Evidence from Admission lotteries. Journal of Health Economics, 32(4), 698-707. https://doi.org/10.1016/j.jhealeco.2013.04.001

Levin, A, Lin, C. F., \& Chu, S. (2002). Unit Root tests in Panel Data: Asymptotic and Finite-Sample Properties. Journal of Econometrics, 108, 1-24. https://doi.org/10.1016/S0304-4076(01)00098-7

Li, Y., \& Mora, R. (2016). Re-assessing the Impact of the Grandparents' Income on the Infant Mortality Rate: An Evaluation of the Old Age Allowance Program in Nepal. World Development, 87, 333-348. https://doi.org/10.1016/j.worlddev.2016.07.002

Linden, M., \& Ray, D. (2017). Aggregation bias correcting Approach to the Health-Income relationship: Life Expectancy and GDP per capita in 148 countries, 1970-2010. Economic Modeling, 61, 126-136. https://doi.org/10.1016/j.econmod.2016.12.001 
McCord, G. C., Conley, D., \& Sacks, J. D. (2017). Malaria Ecology, Child Mortality and Fertility. Economic and Human Biology, 24, 1-17. https://doi.org/10.1016/j.ehb.2016.10.011

Ou, H., Yang, C., Wang, T., \& Wu, J. (2016). Life Expectancy and Lifetime Healthcare Expenditures for Type 1 Diabetes: A Nationwide Longitudinal Cohort of incident cases followed for 14 years. Value in Health, 19(8), 976-984. https://doi.org/10.1016/j.jval.2016.05.017

Pfutze, T. (2014). The Efeects of Mexico's Seguro Popular Health Insurance on Infant Mortality: An Estimation with selection on the Outcome variable. World Development, 59, 475-486. https://doi.org/10.1016/j.worlddev.2014.02.008

Tanaka, S. (2015). Environmental regulations on air pollution in China and their impact on Infant Mortality. Journal of Health Economics, 42, 90-103. https://doi.org/10.1016/j.jhealeco.2015.02.004

UNICEF. (2012), UNICEF Reports on Child Deaths, UNICEF.

UNICEF. (2015). At a Glance: Nigeria. UNICEF. New York.

UNICEF. (2016). Why Income Inequalities Matter for Young People's Health: A Look at the Evidence. Working Paper-2016-06.

United Nations Development Programme. (2014). '2014 Human Development Trends by Indicator', Retrieved from http://hdr.undp.org/en/data

WHO. (2017). Fact Sheet on Cholera. WHO

WHO/UNICEF. (2010). Progress on Sanitation and Drinking Water. WHO/UNICEF Joint Monitoring Programme Report.

World Bank. (2017). World Bank Development Indicators.

\section{Notes}

Note $1 .{ }^{1}$ The effects of healthy status on economic growth has been theorized by many scholars as positive. For example, Linden and Ray (2017), World Bank (2017), McCord et al. (2017), Liu and Mora (2016), Bakkeli (2016), Novignon et al. (2015), and Jones et al. (2014) suggest that health status impacts upon their labour supply, labour productivity, and economic growth; because health affects not only the numbers of hours or days that individuals would dedicate to economic activities, but also the very decision of participating in labour force. Again, extent of economic activities is limited for citizens with poor health.

Note 2. ${ }^{2}$ These studies include: McCord et al. (2017), Linden et al. (2017), Lawson and Spear (2016), Ou et al. (2016), Elder et al. (2016), Li and Mora (2016), Buckler et al. (2016), Tanaka (2015), Brock et al. (2015), Maiti and Petrie (2014), and Leuven et al. (2013).

Note $3 .^{3}$ The nations are: Angola, Burkina Faso, Botswana, Burundi, Cameroon, Cape Verde, Central Africa Republic, Chad, Comoros, Congo Democratic Republic, Congo Republic, Cote d'Ivoire, Equatorial Guinea, Eritrea, Ethiopia, Gabon, Gambia, Ghana, Guinea, Guinea Bissau, Kenya, Lesotho, Liberia, Madagascar, Malawi, Mali, Mauritania, Mauritius, Mozambique, Namibia, Niger, Nigeria, Rwanda, Sao Tome and Principe, South Africa, Senegal, Seychelles, Sierra Leone, Somalia, Sudan, Swaziland, Tanzania, Togo, Uganda, Zambia, and Zimbabwe.

Note $4 .{ }^{4}$ For instance, the Democratic Republic of Congo accounted for 10\% of U5M globally (WHO, 2015). These poor health outcomes were attributed to low health spending as an estimated $70 \%$ Congolese have little or no access to healthcare. However, most healthcare in Ghana is provided by government where Ghana's universal health system was described as the most successful in SSA region. This probably accounted for higher LE of 68 years and IMR of 37 per 1,000 live births in Ghana (World Bank, 2017). For Angola, the emphasize on immunization and health spending helped the nation to declared end for yellow fever outbreak with improved health outcomes (WHO, 2017). 


\section{APPENDIX}

Table A1. Hausman Test Summary

\begin{tabular}{|l|c|c|c|}
\hline & Model 1 & Model 2 & Model 3 \\
\hline Chi-value & 36.63 & 36.30 & 66.66 \\
\hline Prob. value & 0.0000 & 0.0000 & 0.0000 \\
\hline
\end{tabular}

Source: Compiled by Author from Stata 13.0

\section{Copyrights}

Copyright for this article is retained by the author(s), with first publication rights granted to the journal.

This is an open-access article distributed under the terms and conditions of the Creative Commons Attribution license (http://creativecommons.org/licenses/by/4.0/). 